\title{
ВЛИЯНИЕ ЛАТЕНТНОЙ ЖЕЛЕЗОДЕФИЦИТНОЙ АНЕМИИ И ЖЕЛЕЗОДЕФИЦИТНОЙ АНЕМИИ У ДЕТЕЙ С ЗАДЕРЖКОЙ ФИЗИЧЕСКОГО РАЗВИТИЯ КОНСТИТУЦИОНАЛЬНОГО ГЕНЕЗА НА ДИНАМИКУ ЛИНЕЙНОГО РОСТА
}

\author{
${ }^{1}$ Скворцова О.В., ${ }^{2}$ Жилякова О.Н. \\ ${ }^{1}$ ГБУЗ СО СГБ №10, Самара \\ ${ }^{2}$ СОДКБ №1 им. Ивановой, Самара
}

Причины и факторы риска развития задержки физического развития конституционального генеза (ЗФРКГ) по сей день требуют более углубленного изучения, т.к. отставание в росте несет за собой отдельные последствия, в ряде случаев негативно сказывающихся на социальной адаптации детей.

Цель: Оценить степень распространенности железодефицитной анемии (ЖДА) и латентной ЖДА (ЛЖДА) у детей с ЗФРКГ при отсутствии других сопутствующих эндокринологических нарушениях.

Материалы и методы: обследованы 60 мальчиков в возрасте 9-13 лет. 30 мальчиков имеют диагноз ЗФРКГ; 30 - контрольная группа.

Проведена оценка, антропометрических данных, гормонального профиля - ТТГ, Т4 свободный, ИПФР - I, кортизол; общий анализ крови, уровень ферритина, оценка биологического возраста, анамнеза.

Результаты: У всех детей показатели гормонального профиля находились в пределах нормальных значений. Эндокринных нарушений, сопутствующих заболеваний, потенциально оказывающих отрицательное влияние на динамику линейного роста выявлено не было. Показатели роста, веса при рождении у всех детей были в пределах нормы. Отставание в росте отмечалось у детей с 3 лет $-5 \%$; с 4 лет в 25\%; с 5 лет - 30\%; с 6 лет - 40\%: Все пациенты имели мезоморфный, пропорциональный тип телосложения. Средний биологический возраст детей с ЗФРКГ имел отставание от паспортного возраста на 2-2,5 года. У 80\% детей вес соответствовал росту, 20\% имели дефицит массы тела не более 3-5\%. Скорость линейного роста в среднем составляла 3,5 - 5 см в год. Показатели SDS роста детей с ЗФРКГ составляли от $-0,5$ до - 2 сигмальных отклонений. По данным ОАК в группе детей с ЗФРКГ в 80\% случаев отмечалось снижение эритроцитарных индексов - MCV, MCH, при нормальном МСНС. Уровень гемоглобина находился в пределах нормальных значений, что говорит о ЛЖДА. У 15 \% детей диагностирована ЖДА легкой степени тяжести. У всех детей провели оценку уровня ферритина. У мальчиков с ЗФРКГ в 60\% он был снижен - 3-7 мкг/л (при норме 10-125 мкг/л). 30\% детей имели уровень ферритина ближе к нижней границе референсного интервала 10-20 мкг/л; 10\% - выше 30 мкг/л. В контрольной группе уровень ферритина ниже референсных интервалов имели $15 \%$ детей.

Выводы: Распространенность ЛЖДА и ЖДА у детей с ЗФРКГ выше, чем у контрольной группы детей, что может говорить о ее возможном влиянии на динамику линейного роста и конечного роста ребенка.

Ключевые слова: задержка физического развития, латентная железодефицитная анемия, железодефицитная анемия 